\title{
Interactive Map of Coronavirus Spread in Croatia
}

\author{
Robert Župan ${ }^{\mathrm{a}, *}$, Stanislav Frangeš ${ }^{\mathrm{b}}$, Adam Vinkovićc ${ }^{\mathrm{c}}$, Lovre Rupićd \\ ${ }^{a}$ University of Zagreb, Faculty of Geodesy, Kačićeva 26, HR-10000 Zagreb, Croatia-rzupan@ @eof.hr, \\ ${ }^{b}$ University of Zagreb, Faculty of Geodesy, Kačiceva 26, HR-10000 Zagreb, Croatia-sfranges@geof.hr, \\ ${ }^{c}$ University of Zagreb, Faculty of Geodesy, Kačićeva 26, HR-10000 Zagreb, Croatia-avinkovic@geof.hr \\ ${ }^{d}$ University of Zagreb, Faculty of Science, Horvatovac 102a, HR-10000 Zagreb, Croatia - lovre.rupic@student.geog.pmf.hr \\ * Robert Župan
}

\begin{abstract}
At the beginning of any crisis, including pandemics, it is very important to provide timely information to expert headquarters at the local and global level so that they can make daily decisions about measures and behavior of the population. Support for this can be a combination of analytical and statistical data together with the locations from which these data were collected. Part of the cartographic visualization deals precisely with the ways of designing and visual presentation based on which it would be clear to the user where the biggest hotspots and the biggest changes are compared to the previous period. The paper describes the origin and proposal of the original dashboard for monitoring the COVID pandemic in Croatia. The dashboard contains and combines thematic data and displays it with the layout and design carefully determined. The goal is for the data to be implemented as soon as it is available to the public. Similar works available on the Internet are also shown. The entire course of making the dashboard for the COVID pandemic and dissemination data is described, as well as data sources, software, problems encountered and solutions.
\end{abstract}

Keywords: dashboard, cartography, visualization, style

\section{Introduction}

Today's hyper globalized, connected and constantly changing world, in which adaptation to new extreme and radically different situations and lifestyles is nothing new, is mostly shaped and changed through crises like the one that hit it in 2020 and which, unfortunately, it continues. These are the coronavirus pandemic (COVID-19 pandemic), the current pandemic of the new respiratory disease COVID-19 and the first officially declared pandemic after the swine flu pandemic in 2009, which appeared in late 2019 in the Chinese megacity of Wuhan (in the Chinese province of Hubei), to date has spread around the world and which, as of January 12, 2021, infected a total of $91,375,751$ people, of whom $1,954,565$ died. (Wikipedia, 2021). Building on the first sentence of the introduction, i.e., the fact that all the consequences of changes in one part of the world (in this case China) are felt very quickly in almost all other parts, the Republic of Croatia was not deprived of all direct and indirect consequences of the coronavirus pandemic. With the fact that, in the period from February 25, 2020 (the first confirmed case of coronavirus infection in Croatia) to January 12, 2021, a total of 220,982 people were infected in Croatia, of which 4,446 died. Compared to the same periods in 2019 (mostly November), GDP decreased by $15.4 \%$ and $10.0 \%$ in II. and III. quarter decrease in volume of industrial production by $-1.7 \%$, decrease in normal economic activities of business entities, decrease in exports by $3.2 \%$ and imports by $9.3 \%$, increase in the number of deaths by $32.9 \%$ (observing only November), decrease in number of transported passengers by $42.2 \%$ in III. quarter of 2020, a decrease in the number of tourist arrivals and overnight stays by about $80 \%$ in October 2020, rising unemployment, etc (DZS, 2021).
All these negative trends have encouraged the mobilization of state authorities and a wide range of experts and scientists, all for the purpose of monitoring, controlling, and stopping the further spread of the pandemic. Among all possible approaches to coronavirus by various scientific disciplines, one of them is of particular interest to experts in the field of GIS technologies and geoinformatics (especially surveyors and geographers), and it would be mapping and displaying data on infection through cartographic representations or digital). Accordingly, the aim of this seminar was to create an interactive map of the spread of the coronavirus pandemic (COVID-19) in the Republic of Croatia, i.e., through this technical report to explain all procedures and the entire course of its development (from data collection and selection of software and tools for its development), steps and procedures for its development and, ultimately, its final design and publication.

\subsection{Interactive map}

The application of computer technology in cartography and production of cartographic products is never more important and under ever greater pressure from evergrowing user requirements, it is necessary to present a few basic facts about interactive maps (Župan and Vračar, 2014), not only published ones, but also created and designed through online sources (interactive web maps), as well as look at some of the most famous examples of maps to monitor the spread of coronavirus (COVID-19) in the world and Croatia.

\subsection{Basic Features of Interactive Maps}

It is necessary to set a unique definition for the term interactive map (i.e., interactive web map). Namely, the development of multimedia cartography, which is recording rapid development in parallel with computer 
technologies, as well as increasing availability of data, software and tools on the Internet, making cartographic displays, and thus interactive maps, began to deal with an increasing number of cartographic experts and "laymen", which resulted in numerous definitions and interpretations of the term interactive map (Župan and Vračar, 2014). Perhaps the most complete definition of the term interactive map would be that it is an interactive cartographic system for searching and displaying information consisting of one or more maps stored in raster or vector format and a database with descriptive data about individual objects which, in addition to maps, also contains software to search and display maps and descriptive data, text, and other multimedia attachments. From the aspect of their use, i.e., their functionality and content they display, interactive web maps can be divided into static and dynamic, where there are several different combinations of static (display static and immutable data, but can have the ability to view without interactivity with the user or interactively user interface and / or content) and dynamic maps (displaying dynamic and ever-changing data in real time, but may have either the ability to view without interactivity with the user or an interactive user interface and / or content) (PMF Repository, 2020).

\subsection{Examples of Interactive Coronavirus Spread Maps}

In the sea of interactive maps of the spread of the coronavirus pandemic (COVID-19) at the level of the whole world and the Republic of Croatia, four interactive web cartographs made either by independent experts in GIS and geoinformatics or by world organizations, authorities and institutions by action directly related to virus control.

At the global level, an interactive map (dashboard) of the World Health Organization (WHO) and an interactive map (dashboard created in the web application ArcGIS Dashboards) of the Center for Systems Science and Engineering (CSSE) of John Hopkins University in Baltimore can be singled out, while at the level of the Republic of Croatia, an interactive map (dashboard) of the Official Website of the Government for timely and accurate information at URL 3, and an interactive map (dashboard made in the ArcGIS Dashboards web application) of the Croatian software company GDi can be distinguished (Figure 1).

Analysing the main features of their functionality and the data they display, all these examples are static maps that display static and immutable data (which are changed manually usually every 24 hours), but have an interactive user interface through which it is possible to change the map background, the way display of given attributes, scale, etc.
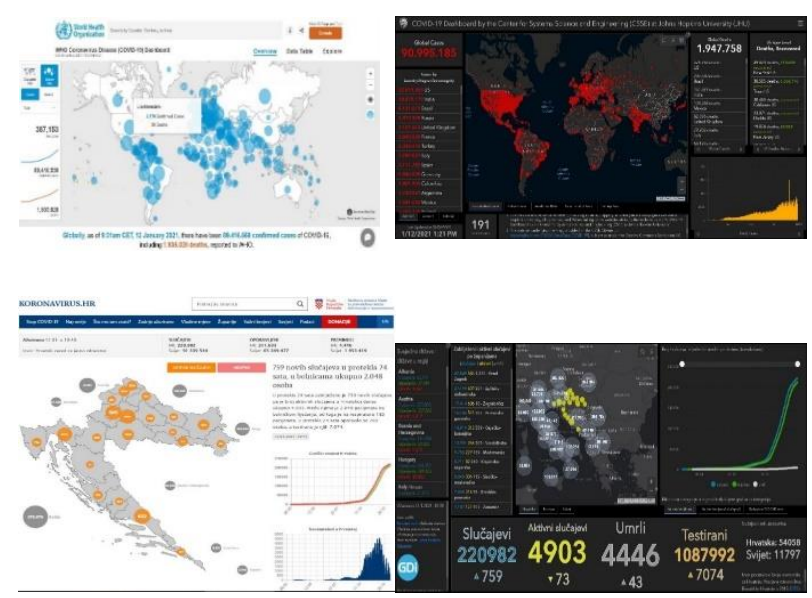

Figure 1. User interface of the WHO Dashboard (top left), John Hopkins University Center for Systems Science and Engineering (CSSE) (top right), Koronavirus.hr site (bottom left) and GDi Ltd. (bottom right), (URL 1, URL 2, URL 3, and URL 4)

In addition to interactive cartographic displays, these examples, as well as most other examples of dashboards related to coronavirus spread, contain accompanying numerical and graphical attachments that refine the maps themselves and allow time tracking of coronavirus spread over time. The problem that all these interactive maps and dashboards have is the fact that they contain only the latest data sorted by spatial units (countries in the case of the whole world and continents or regions and counties in the case of countries), while previously published data (from of the previous day) are deleted, which makes it impossible to follow the change of a certain attribute (in this case the spread of coronavirus) over time through an interactive cartographic display. The interactive map, i.e., the dashboard made as part of this seminar, differs from the previous examples in this segment, i.e., through multimedia attachments (animated attachments of coronavirus spread stored in the form of videos), while in almost all other segments it is related to previous examples.

\section{Formation and Design of the Dashboards}

The entire process of planning, creating, and publishing an interactive web map, or dashboard (ArcGIS Dashboard) for monitoring the spread of coronavirus, can be divided into four phases:

a) Selection of data sources, their collection and selection of ways of their visualization

b) Selection of appropriate and appropriate software for organizing, editing and displaying data

c) Creation of animated and interactive cartographic representations and other contents and their transfer (upload) to the ArcGIS Online internet platform

d) Create a dashboard (ArcGIS Dashboard) and add and configure its contents

e) Final presentation of the control panel and its content and functionality 


\subsection{Data Collection}

Due to the huge interest of the public, profession and state authorities around the world, including Croatia, a large number of organizations on the Internet have developed data collection systems on the spread of coronavirus in the last year, and in some cases, there are significant differences in data collection and interpretation methodology. With this in mind, as well as the fact that only data from reliable and verified sources should be used on the Internet, it was determined that the two main data sources for this seminar will be the Official Government Website for Timely and Accurate Information on Coronavirus (Koronavirus.hr) and Croatian Institute of Public Health (HZJZ) which have adapted their methodology of pandemic monitoring and data collection to the umbrella regional health organizations (European Center for Disease Prevention and Control - ECDC) and the World Health Organization - WHO). On the URL 3, open (machine-readable data) are available in JSON format (JavaScript Object Notation) in five categories, of which data in four categories were used: data for Croatia and the world (cumulative - for all days), for Croatia and the world (latest, for that day), for all counties (cumulatively - for all days) and for all counties (latest, for that day) (Figure 2).

\section{Otvoreni (strojno čitljivi) podaci}

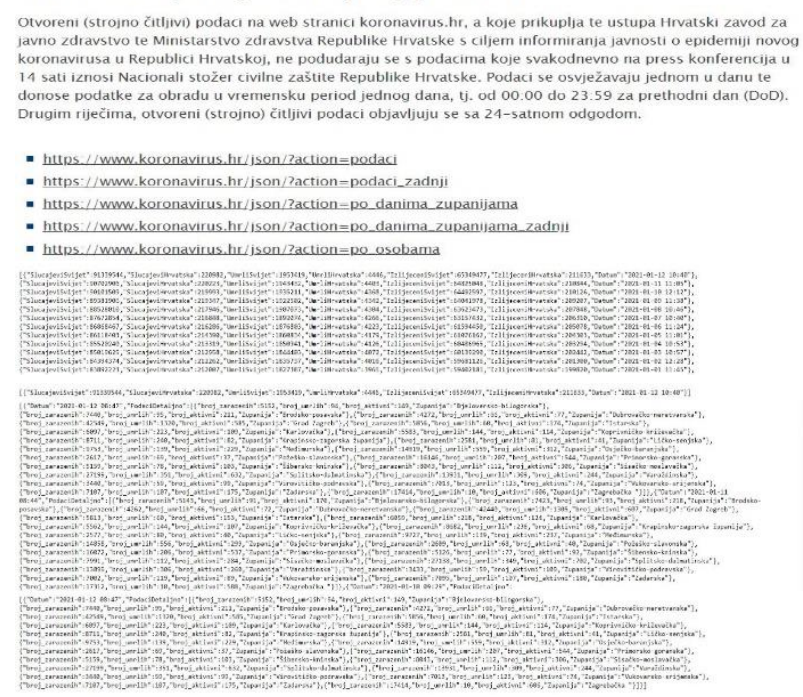

Figure 2. Open (machine readable) data in the four categories used in JSON format (URL 3)

Although there are tools that enable the conversion of JSON files and their further use in GIS software compatible format, it was decided to convert the same data to Excel format via online tools for conversion to other formats, which facilitates the use and manipulation of data and their entry into software (Figure 3).

The Croatian Institute of Public Health's website used somewhat more detailed data than those available on the Koronavirus.hr website, which is published and updated every few days, but exclusively at the level of the whole of Croatia and stored in Excel format (Figure 4).

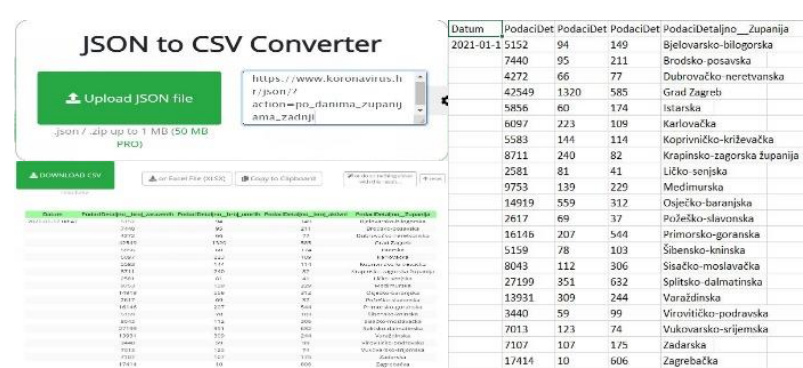

Figure 3. Conversion of JSON data by counties (left) to Excel format (right) using the online conversion tool

(URL 3 and URL 5)

\section{COVID-19 - izvješće HZJZ-a}

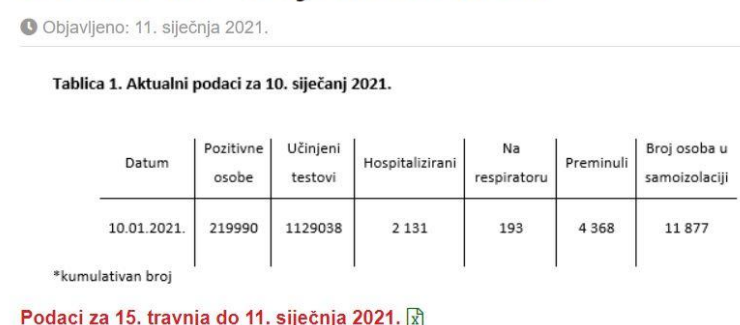

Figure 4. CNIPH data (cumulative), URL 6.

In addition to the epidemiological data (on the number of infected, dead, active cases...), relevant data for this topic would be information on the location and operation of coronavirus (COVID-19) test centers in Croatia (organized in tables) and a chronological overview of prescribed epidemiological measures by counties (also available and collected through the Koronavirus.hr website) (Figure 5). The last set of data used refers to data on area (in $\mathrm{km}^{2}$ ) and population of counties (estimated in 2019) taken from the pages of the Central Bureau of Statistics (CBS) and the Central Register of Spatial Units of the State Geodetic Administration (SRPJ SGA).

In accordance with all collected data and available software, it was decided to present data on the spread of coronavirus in Croatia in four ways: through three interactive maps of the latest information on the state of the coronavirus pandemic (to show general epidemiological indicators, standardized epidemiological indicators and test center information and prescribed epidemiological measures), four animated cartographic representations (to show the movement of the cumulative number of infected, dead, active cases and incidence rates per 100,000 inhabitants), numerical indicators (for the world and Croatia) and four diagrams (for graphical presentation and chronological monitoring of epidemiological indicators on at the level of the entire Republic of Croatia). 


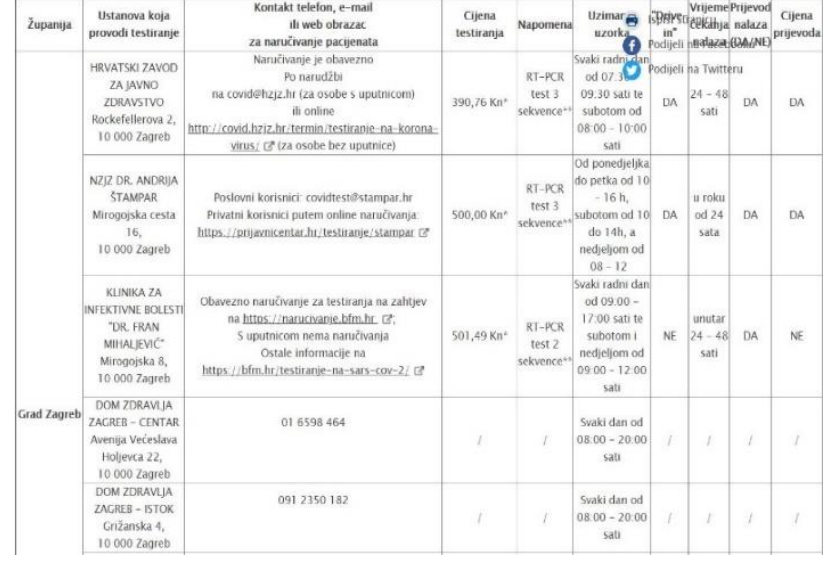

Figure 5. Example of a tabular overview of test center information (URL 3)

The already mentioned fact that this is data that is published and supplemented with a 24-hour delay (Koronavirus.hr) or every few days (HZJZ) and the realization that in the Republic of Croatia, but also in the world, there is no single system for collecting and displaying data about real-time (live) coronavirus makes it very difficult to work with such data and requires their daily updating and new entry, which is why for now the new data (from today) will be obsolete tomorrow. Therefore, it was decided that, similarly to the census, a critical moment be determined, i.e., that the research included and cartographically presented spatial units add attributes (data on the spread of coronavirus) found, taken over and organized at the time of the seminar. For animated cartographic representations, this time coverage refers to the period from March 21, 2020, i.e., from the beginning of the official data collection, to December 31, 2020. For interactive cartographic representations and stated numerical contributions and indicators, which referred exclusively to that day, the reference date was taken as January 07, 2021. Finally, the then available data taken from the CNIPH website for the period from April 15,2020 were used to create the diagram. to January 03, 2021.

\subsection{Software}

After all the necessary conversions and data downloads, the next phase of the seminar included the selection of appropriate software for organizing and working with this data. With the rapid development and commercialization of GIS technology, a wide selection of free and more sophisticated tools and software for creating interactive maps has found its way onto the market. The previous experience of data organization and creation of interactive cartographic displays, as well as general knowledge of working in various GIS software and their availability, it was decided, first, that all data be organized and edited in Microsoft Excel before entering GIS software. Regarding the development of the basic elements of the entire seminar (interactive and animated maps), it was decided to carry out these procedures in two software modules (ArcMap 10.7 and its more modern and sophisticated version, ArcGIS Pro) which are part of ESRI's review software package, editing, creating, and analysing ArcGIS geospatial data. Both programs, in addition to their mutual advantages and disadvantages, were used alternately during the seminar with a slightly greater emphasis on the work in ArcGIS Pro, in which somewhat more complex operations with spatial layers, editing data in attribute tables and data transfer at ArcGIS Online. By transferring all layers, files, interactive maps and animations to ArcGIS Online, a web platform that enables sharing and searching of geospatial data and content and their further configuration in web applications (ArcGIS Dashboards, Experience, Story Maps, Urban (), the ArcGIS Dashboard was created. , a web application in the form of a dashboard that, using a combination of intuitive and interactive data visualizations, offers organizations, individuals and other users the basis for decision-making, trend visualization and, if possible, real-time monitoring (ESRI 2021).

\subsection{Cartographic and Dashboard Design}

As the most complex part of the dashboard, the first approach was to create four animated maps (for the cumulative number of infected, dead, active cases and incidence rate per 100,000 inhabitants for counties) which were mentioned in the previous chapter to cover only 2020 (i.e., from March 21, 2020 to December 31, 2020). The first step in creating animated maps was to prepare attribute data for Microsoft Excel and enter them later, along with spatial data ("County" shapefile) via the ArcCatalog window into the spatial database (Geodatabase) (Figure 6).

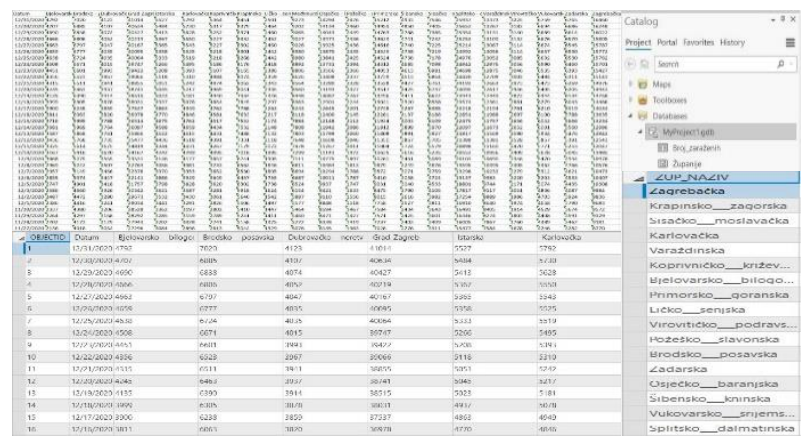

Figure 6. Entering the attribute table with epidemiological data (left) and the shapefile of the "County" (bottom right) in the ArcGIS Pro Catalog window in the shared spatial database (File Geodatabase) (top right).

Entering an Excel spreadsheet in ArcGIS Pro automatically changed the county names in the header (column names in the attribute tables in ArcMap and ArcGIS Pro must not contain spaces or dashes), so the county names in the "County" shapefile attribute table also had to be adjusted as these names could later be used to add non-spatial data (on coronavirus) to spatial data (the "County" layer). Data manipulation was continued in a 
similar way and using the listed software to the form usable for the dashboard. Joining epidemiological data depicts Figure 7.

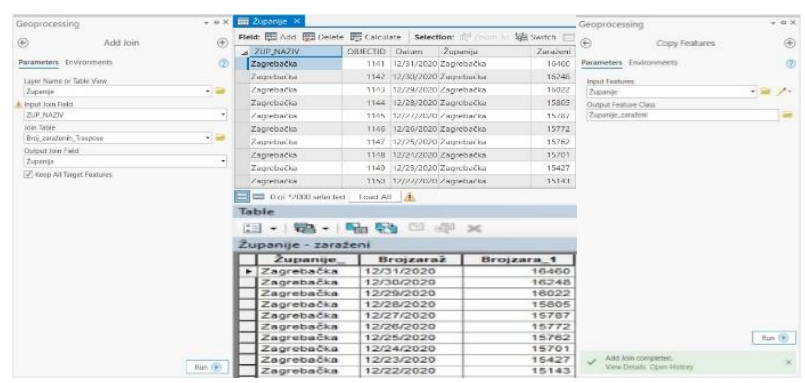

Figure 7. Adding epidemiological data to the "County" layer (left), attribute table after joining and exporting a new layer and opening the attribute table without unnecessary columns.

As a way of displaying the attributes of coronavirus spread over time, the method of proportional symbols was chosen which, unlike graduated Symbols, represent quantitative values as a series of unclassified symbols displayed according to their specific value (Figure 8).

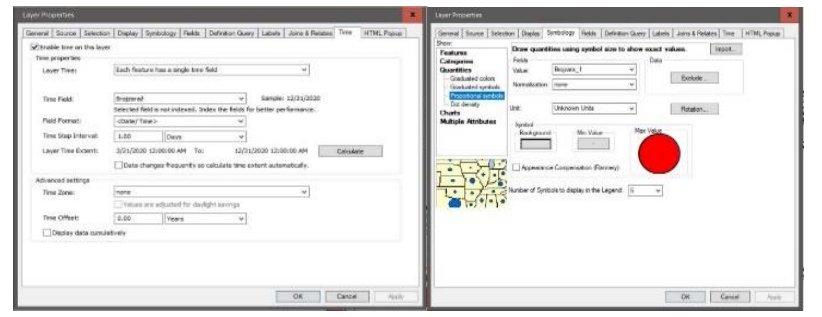

Figure 8. Activation of the time component of the layer (left) and selection of the display (symbology) for epidemiological data (right).

The next step in creating the animation was to configure the animation settings, and it consisted of opening the Animation Toolbar, creating a new time animation (Create Time Animation option) and adjusting the basic controls and animation settings (Animation Controls option). limiting its duration to 20 seconds to reduce the size of the video file) (Figure 9).

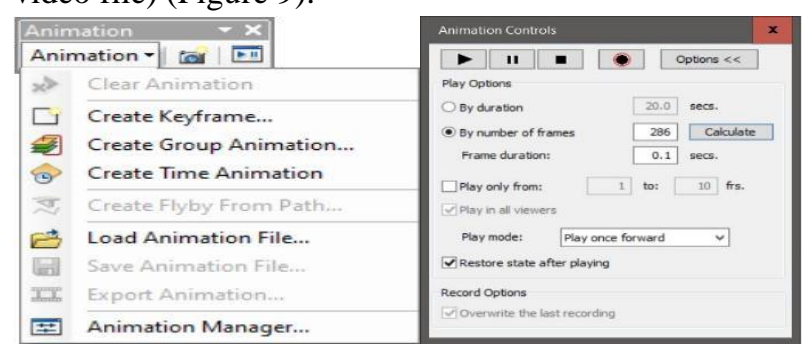

Figure 9. Creating a new animation in the toolbar (Animation Toolbar - Create Time Animation) (left) and setting the duration of the animation to 20 seconds (right)

The last step before saving the animation and exporting it (Export) was just editing the content within its frames (adding county names, legends, scales, days to which the displayed data and sources refer). Although the option of adding names to Label Features is almost always used in such procedures, county names are added to the animation display itself by simply adding text (Insert - Text). As the animation is exported in Data View, not Layout View, which is why it is not possible to add a legend to it, its insertion into the animation is done by cutting the legend from the table of contents (Table of Contents) (Snipping Tool) and inserting as images Picture). Like county names, the scale (in numerical form) and data source are also inserted into the animated map via the Insert - Text option. The time component of the animation, i.e., the day to which the displayed data refers, was added to the animation through the time slider settings (Time Slider Time Slider Options - Display Date Format - Show time on map display) (Figure 10).

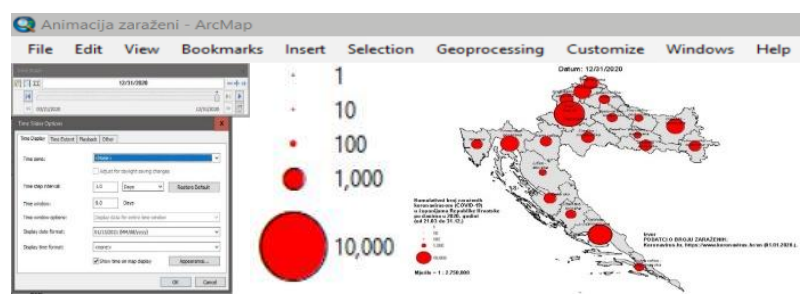

Figure 10. Adding county name, legend, numerical scale and source (Insert) (top), date (Time Slider) (left) and final layout of one clip (frame) of animation (right)

The last step in creating an animation is to adjust the settings for exporting the animation (Export Animation), i.e., determining the format in which the animation will be stored (audio video format - AVI - Audio Video Interleave is selected), selecting the compression type (no compression option is selected - Full Frames (Uncompressed)) and, ultimately, upload to YouTube, so that the animation as embedded content can later be inserted into the dashboard (ArcGIS Dashboard) (Figure 11).

The almost identical procedure of data processing and animation was repeated for other animations (movement of cumulative number of deaths, active cases and incidence rate per 100,000 inhabitants), which is why it is not necessary to explain the procedure of their creation.

The next, software, time and logistically much simpler procedure was to create three interactive cartographic displays of the latest information on the state of the coronavirus pandemic to display general epidemiological indicators (stored in their original form), standardized epidemiological indicators (recalculated and standardized according to general county data), primarily area and population and information on test centres and prescribed epidemiological measures (digitized and associated with appropriate attributes depending on their location in space), which, due to the already mentioned limitations of the data collection methodology, are shown only for one day (January 07, 2021). 

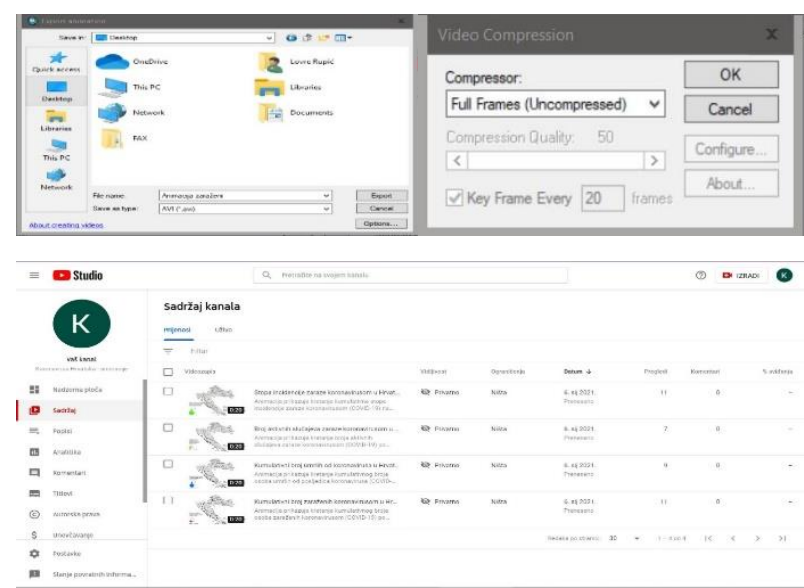

Figure 11. Configuring the animation export settings (above) and uploading all four created animations to the YouTube channel

Since interactive and animated cartographic representations were conceived as the central parts of the dashboard around which its other elements would be based, it was necessary to organize them in such a way that, on the one hand, they occupied the largest part of the dashboard and, on the other hand, they do not take up too much space and thus damage the integrity and visual harmony of the dashboard. This problem was solved by grouping three interactive maps and four animations into one common stack on which one element is displayed at the same time, and the other six can be accessed by clicking on the name below the element and selecting in the drop-down menu (Figure 12).

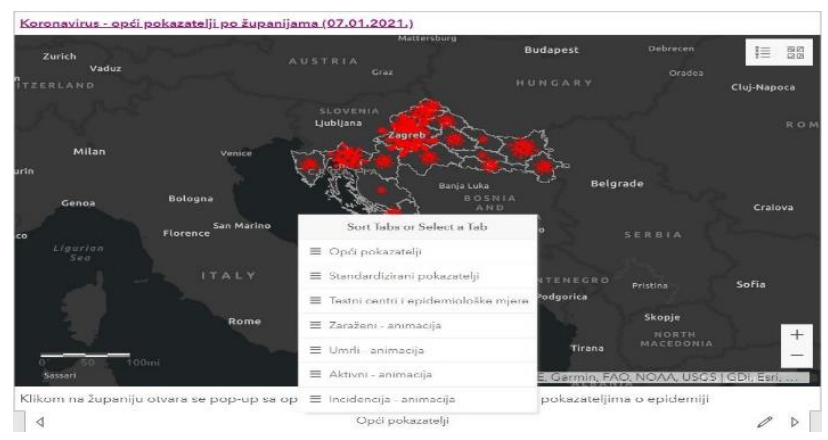

Figure 12. Grouping seven interactive and animated cartographic displays into a common stack and access to other elements in the bundle

Selecting the option of adding a Serial Chart, which enables monitoring of the spread of coronavirus in the Republic of Croatia over time (from April 15, 2020 to January 03, 2021), opens a menu in which the data itself is set (setting the date value on the $\mathrm{x}$-axis and data on the spread of coronavirus to the $y$-axis, grouping of individual dates into months), position of the legend and horizontal orientation of the diagram, the ability to change the time frame of the displayed data, appearance and characteristics of the $x$ and $y$-axes (axis name, text size and colour...), type (line diagram) and the layout of the diagram lines (colour, name and features of the text) and the name and short description of the diagram (instructions for its use), so that the four created diagrams are grouped into one bundle in the same way as cartographic display (Figure $13)$.

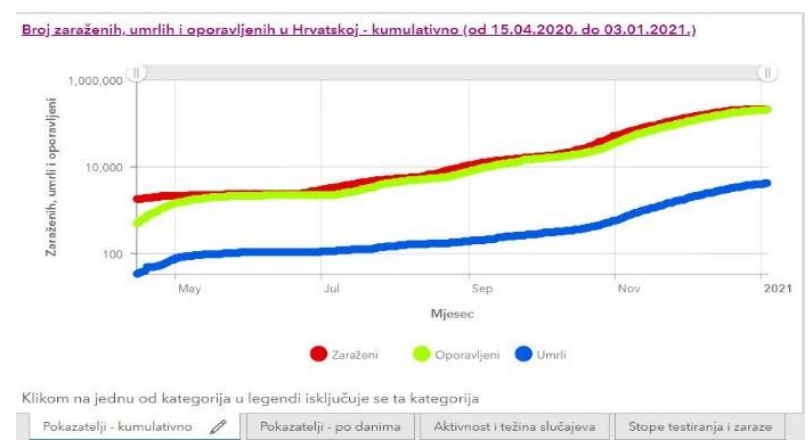

Figure 13. Editing and adjusting data display options, legends, $\mathrm{x}$ and $\mathrm{y}$-axis assignments, Serial Chart names and descriptions (top) and grouping four diagrams into one stack (bottom)

In terms of functionality and the ability of users to interact with the dashboard, each element of the dashboard, above all, offers the ability to view data in their original scope (as originally placed on the dashboard) or expand and occupy the entire screen (by pressing the expand button in the upper right corner of each element).

There are still some shortcomings in which this dashboard could be further improved in the future. For example, data on numerical indicators and representations of the number of infected people would be good to include indicators and representations by age - gender composition. Also, it would be desirable to implement on the dashboard data on the effects of the epidemic on the main socio-economic indicators in the Republic of Croatia, as well as projections and scenarios for the further course of the epidemic. The last two possible improvements would be, the addition of data on the spread of the coronavirus epidemic in the neighbourhood of the Republic of Croatia, and, when such a system would be established, the presentation of data on the spread of the epidemic in real time. However, it should be borne in mind that these are improvements which, due to the methodology of data collection, and the fact that their implementation greatly exceeds the time, organizational and software capabilities of this seminar (such projects and improvements are dealt with by multimember teams of experts), were simply not possible to implement.

Link for dashboard (Interactive map of coronavirus spread (COVID-19) in the Republic of Croatia) at:

https://www.arcgis.com/apps/opsdashboard/index.html\#/ 2e83851da5f14fbca0d4db97d84a53a1

\section{Conclusion}

Creating an interactive map of coronavirus spread (COVID-19) is a complex and current task through which 
experts in the field of GIS and geoinformatics can contribute to the fight against viruses and informing the professional and public that has changed the way of life and human manner and the functioning of the world as a system. By creating this seminar, the implementation of which was conceived through five steps, a dashboard (ArcGIS Dashboard) was made for the spread and current state of the coronavirus epidemic (COVID-19) in the Republic of Croatia, which combines different ways of visualizing data (through interactive and animated maps, numerical indicators, and diagrams), and which, like any other such product (web application), is open to further improvements and expansions in the future.

\section{References}

Državna geodetska uprava (DGU) 2021. Registar prostornih jedinica, https://dgu.gov.hr/registarprostornih-jedinica-172/172 (January 15, 2021).

Državni zavod za statistiku (DZS) 2021. Učinci pandemije bolesti COVID-19 na društveno-ekonomske pokazatelje, https://www.dzs.hr/Hrv/Covid-19/pocetna.html (January 15, 2021).

Državni zavod za statistiku (DZS) 2020. Procjena stanovništva Republike Hrvatske u 2019., https://www.dzs.hr/ (January 15, 2021).

Environmental Systems Research Institute (ESRI) 2021. ArcGIS Dashboards - Resources, https://www.esri.com/en-us/arcgis/products/arcgisdashboards/resources (January 15, 2021).

Environmental Systems Research Institute (ESRI) 2021. ArcMap-Documentation, https://desktop.arcgis.com/en/arcmap/ (January 15, 2021).

Environmental Systems Research Institute (ESRI) 2021. ArcGIS Online - Resources, https://www.esri.com/enus/arcgis/products/arcgis-online/resources (January 15, 2021).

Environmental Systems Research Institute (ESRI) 2021. ArcGIS Pro - Resources, https://www.esri.com/enus/arcgis/products/arcgis-pro/resources (January 15, 2021).

PMF Repository 2020. Geografska karta; Podjela karata; Elementi karte, https://www.pmf.unizg.hr/_download/repository/KOG_ 2_2020.pdf (January 15, 2021).

URL 1. WHO Coronavirus Disease (COVID-19) Dashboard, https://covid19.who.int/ (January 15, 2021).

URL 2. COVID-19 Dashboard by the Center for Systems Science and Engineering (CSSE) at Johns Hopkins University (JHU), https://gisanddata.maps.arcgis.com/apps/opsdashboard/i ndex.html\#/bda7594740fd40299423467b48e9ecf6 (January 15, 2021).

URL 3. Službena stranica Vlade za pravodobne i točne informacije o koronavirusu, https://www.koronavirus.hr/ (January 15, 2021).
URL 4. ArcGIS Dashboards, https://gdionline.maps.arcgis.com/apps/opsdashboard/in dex.html\#/47451c9cab8649c49ebfad8db4f64aec (January 15, 2021).

URL 5. JSON to CSV Converter Online, https://jsoncsv.com/ (January 15, 2021).

URL 6. Koronavirus - najnoviji podatci | Hrvatski zavod za javno zdravstvo, https://www.hzjz.hr/priopcenjamediji/koronavirus-najnoviji-podatci/ (January 15, 2021).

Wikipedia, 2021. Pandemija koronavirusa 2019./20., https://hr.wikipedia.org/wiki/Pandemija_koronavirusa_2 019./20. (January 15, 2021).

Wikipedia, 2021. Pandemija koronavirusa u Hrvatskoj 2020 ,

https://hr.wikipedia.org/wiki/Pandemija_koronavirusa_u _Hrvatskoj_2020.\#Statistike (January 15, 2021).

Župan, R., Vračar, J., 2014. Primjena tehnologije GIS-a za izradu interaktivne web karte Sveučilišta u Zagrebu, Geodetski list 68 (91), $291-308$. 